\title{
Spousal concordance in academic achievements and IQ: a principal component analysis
}

\author{
Yue Pan ${ }^{1}$, Ke-Sheng Wang ${ }^{2 *}$ \\ ${ }^{1}$ Department of Mathematics and Statistics, College of Arts and Sciences, East Tennessee State University, Johnson City, United \\ States; \\ ${ }^{2}$ Department of Biostatistics and Epidemiology, College of Public Health, East Tennessee State University, Johnson City, United \\ States. \\ E-mail: *wangk@etsu.edu
}

Received 10 May 2011; revised 8 June 2011; accepted 16 June 2011.

\begin{abstract}
Assortative mating, the tendency for mate selection to occur on the basis of similar traits plays an essential role in understanding the genetic variation on academic achievements and intelligence (IQ), it is also an important mechanism explaining spousal concordance. We used a subset of The Collaborative Study on the Genetics of Alcoholism sample to study the mating patterns in 84 pairs of spouses from Caucasian families with their academic achievements (reading, spelling, arithmetic, vocabulary and comprehension) and IQ (verbal IQ, performance IQ and full scale IQ). Simple correlation analysis showed that 6 of these 8 traits revealed evidence of spousal correlation $(P<0.05)$. The first principal component (PC1) of husbands explains $73.61 \%$ for the variation in the eight variables, which has high loadings from reading, spelling, arithmetic, verbal IQ and full scale IQ while PC1 of wives explains $72.86 \%$ for the variation in the eight variables, which has high loadings from reading, spelling, verbal IQ and full scale IQ. There was highly significant positive correlation between spouses by PC1 $(P<0.0001)$. The new variable PC1 may be important in spousal concordance and mate selection in society and act upon achievements and intelligence levels.
\end{abstract}

Keywords: Academic Achievements; IQ; Spousal Concordance; Principal Component Analysis

\section{INTRODUCTION}

Mate selection is a major biological event and whose outcome is a substantial determinant of an individual's return on his/her whole reproductive investment [1]. Assortative mating, the tendency for mated pairs to be more similar to each other phenotypically than would be expected if they were married or mated at random, occurs for a variety of phenotypic traits, including both genetically determined traits and environmentally determined traits [2]. Assortative mating plays an essential role on society and the individual. It will increase the population variance of a given trait and the proportion of individuals who are homozygous for the trait. At the individual level, assortative mating can influence the course and outcome of marriage, in addition to determining the genetic and biological makeup and parenting of offspring [3].

Assortative mating has been shown for height [4-6], attitude domain of personality [7-12], social factors [13,14], smoking habits [15-17], and antisocial behavior and psychiatric disorder [2,17-22]. Assortative mating, the tendency for mate selection to occur on the basis of similar traits plays an essential role in understanding the genetic variation on academic achievements and intelligence (IQ), it is also an important mechanism explaining spousal concordance. At present, assortative mating with respect to IQ has been long standing interest to researchers, there are number of analyses and studies [13, 14, 23-29]. However, few studies focus on the combination of IQ with academic achievements, and no study has been found to use principal component analysis in assessing spousal concordance of academic achievements and IQ.

In the present study, we investigated the spousal concordance with respect to eight variables which represent the people's academic achievements and IQ using both simple correlation analysis and multivariate analysis.

\section{METHODS}

\subsection{Subjects and Variable Selection}

The Collaborative Study on the Genetics of Alcoholism 
Table 1. Characteristics of husbands and wives, correlation analysis and paired-t-test.

\begin{tabular}{lccccccc}
\hline \multicolumn{1}{c}{ Variable } & $\mathbf{N}$ & husband-mean & wife-mean & corr-coef & Pc & T & Pt \\
\hline reading(standard) & 84 & 99.66667 & 99.2619 & 0.60115 & $<0.0001$ & 0.28 & 0.7784 \\
spelling(standard) & 84 & 93.79762 & 100.3571 & 0.5804 & $<0.0001$ & -4.03 & 0.0001 \\
arithmetic(standard) & 84 & 101.4048 & 99.72619 & 0.33865 & 0.0016 & 0.95 & 0.3429 \\
vocabulary(scaled) & 84 & 10.14286 & 10.25 & 0.43152 & $<0.0001$ & -0.33 & 0.7441 \\
comprehension(scaled) & 84 & 10.67857 & 9.92857 & 0.16864 & 0.1252 & 1.8 & 0.0749 \\
verbal IQ(scaled) & 84 & 105.1905 & 101.4524 & 0.27463 & 0.0115 & 2.05 & 0.044 \\
performance IQ(scaled) & 84 & 102.9286 & 102.2619 & 0.14197 & 0.1977 & 0.38 & 0.7015 \\
full scale IQ(scaled) & 84 & 104.381 & 101.8691 & 0.2809 & 0.0096 & 1.49 & 0.1404 \\
\hline
\end{tabular}

$\mathrm{N}=$ number of individuals. Corr-coef $=$ Correlation coefficient between spouses; $\mathrm{Pc}=p$-value of correlation coefficient between spouses; $\mathrm{T}=$ t-statistics of paired-t test. $\mathrm{Pt}=p$-value of paired-t test between spouses.

(COGA) is a multisite collaboration with the goal of identifying genes contributing to alcoholism and related phenotypes [30]. A total of 2,282 individuals from 262 multiplex alcoholic families are available for genetic analyses. Phenotypes include alcohol dependence, personal traits, academic achievements and IQ.

In order to conduct the analysis for achievement and intelligence variables, we chose 8 variables in the COGA data sets which represent the spouses' standard achievements and intelligence level, as measured by the Wechsler Adult Intelligence Scale-Revised (WAIS-R). The WAIS [31,32] is a traditional intelligence test with high test-retest reliability, stability across different age spans, concurrent and predictive validity and substantial heritability [33]. The 8 variables are reading (standard), spelling (standard), arithmetic (standard), vocabulary (scaled), comprehension (scaled), verbal IQ (VIQ), performance IQ (PIQ) and full scale IQ (FSIQ) [34,35]. From the 262 multiplex families, we found 84 independent Caucasian spouse pairs with these 8 achievement and intelligence variables (Table 1).

\subsection{Statistical Analysis}

PROC UNIVARIATE was used to detect the normality of these continuous traits and outlier. Paired t-test was conducted to compare means of 8 variables between husbands and wives. Then, spouse resemblance was assessed by using Pearson correlation for each variable. Finally, we used principal component analysis (PCA) to generate PC scores as new variables to represent the achievement and intelligence level for husbands and wives, and test if there is spousal concordance for each PC score. All the statistical analyses were performed using SAS version 9.2.

\section{RESULTS}

\subsection{Normality Test and Gender Difference}

Based on the results of PROC UNIVARIATE, all 16 tests (8 variables for husbands and wives, respectively) showed that all the variables were normally distributed and no outlier was found. Because these traits were normally distributed, we used paired t-test to test the gender difference. The paired t-test showed that husbands had lower scores for spelling and higher scores for verbal IQ than wives (Table 1) while other variables did not differ between male and female spouses.

\subsection{Spousal Concordance Based on Simple Correlation Analysis}

Pearson correlation (Table 1) showed that husbands and wives had significant positive correlation for reading $(r$ $=0.60115, P<0.001)$, spelling $(r=0.58040, P<0.001)$, arithmetic $(r=0.33865, P=0.0016)$, vocabulary $(r=$ $0.43152, P<0.001)$, verbal IQ $(r=0.27463, P=0.0115)$ and full scale IQ $(r=0.28090, P=0.0096)$ but no significant correlations for comprehension $(r=0.16864, P$ $=0.1252)$ and performance IQ $(r=0.14197, P=$ 0.1977).

\subsection{Spousal Concordance Based on Correlation Analysis using PC Scores}

Because most of the variables were significantly correlated with each other, we used principal component analysis (PCA) to generate first and second principal components (PC1 and PC2), which are independent each other. Table 2 showed the principal component loadings for PC1 and PC2 in husband and wife groups. We found that there was a $86.37 \%$ of accumulative contribution ratio for male spouses by PC1 and PC2 while there was a $87.99 \%$ of accumulative contribution ratio for female spouses by PC1 and PC2, which revealed that PC1 and PC2 could explain $86.37 \%$ (PC1 $=73.61 \%$, PC2 = $12.76 \%$ ) of the achievements and intelligence in male spouses while $87.99 \%(\mathrm{PC} 1=72.86 \%$, PC2 $=15.13 \%)$ of the achievements and intelligence in female spouses.

In the PC1 cases, for husband variables, PC1 has high loadings from spelling (0.488106), reading (0.432491), 
Table 2. Principal components loadings for husbands and wives.

\begin{tabular}{|c|c|c|}
\hline Husband variables & PC1 & PC2 \\
\hline reading (standard) & 0.432491 & -0.196181 \\
\hline spelling (standard) & 0.488106 & -0.442378 \\
\hline arithmetic (standard) & 0.394913 & -0.458365 \\
\hline vocabulary (scaled) & 0.081872 & 0.068215 \\
\hline comprehension (scaled) & 0.071645 & 0.108926 \\
\hline verbal IQ (scaled) & 0.422952 & 0.489498 \\
\hline performance IQ (scaled) & 0.271721 & 0.309194 \\
\hline full scale IQ (scaled) & 0.392671 & 0.451651 \\
\hline Wife variables & PC1 & PC2 \\
\hline reading (standard) & 0.470387 & -0.460293 \\
\hline spelling (standard) & 0.480109 & -0.442682 \\
\hline arithmetic (standard) & 0.356364 & 0.068955 \\
\hline vocabulary (scaled) & 0.07925 & 0.009375 \\
\hline comprehension (scaled) & 0.059798 & 0.047292 \\
\hline verbal IQ (scaled) & 0.396589 & 0.119958 \\
\hline performance IQ (scaled) & 0.315482 & 0.658417 \\
\hline full scale IQ (scaled) & 0.393151 & 0.370378 \\
\hline
\end{tabular}

PC1 = First principal component. PC2 = Second principal component.

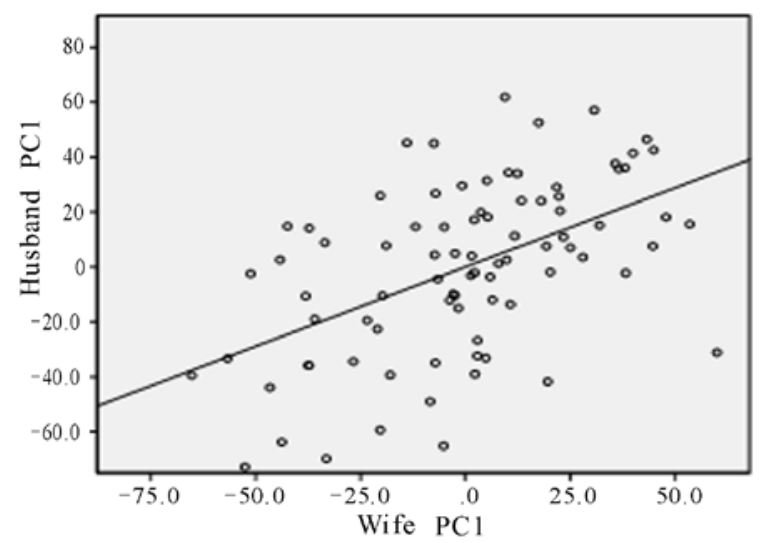

Figure 1. Relationship between husband and wife PC1 scores.

verbal IQ (0.422952), arithmetic (0.394913) and full scale IQ (0.392671). For wife variables, PC1 has high loadings from reading (0.470387), spelling (0.480109), verbal IQ (0.396589) and full scale IQ (0.393151). In the PC2 cases, for husband variables, PC2 has high loadings from spelling $(-0.442378)$, arithmetic $(-0.458365)$, verbal IQ (0.489498) and full scale IQ (0.451651). For wife variables, PC2 has high loadings from performance IQ (0.658417), reading $(-0.460293)$, spelling $(-0.442682)$ and full scale IQ (0.370378).

Figure 1 showed there was a highly significant positive correlation between the PC1 values of paired hus- bands and wives ( $r=0.515, P<0.0001, n=84$ ); whereas the relationship in PC2 between husbands and wives was weak ( $r=0.1952, P=0.0752)$.

\section{DISCUSSION}

The present analyses provide evidence of significant spousal concordance in academic achievements and IQ measured by WAIS-R. Simple correlation analyses showed that 6 (reading, spelling, arithmetic, vocabulary, verbal IQ and full scale IQ) of 8 traits in academic achievements and IQ showed evidence of spousal correlation $(P<0.05)$, while correlation analysis based on the first principal component score (PC1 value) of 8 traits further revealed highly significant spousal resemblance $(P<0.0001)$.

Academic achievements and intelligence, which considered as important hereditary factors, have been commonly observed and studied in genetics. Assortative mating by achievement or intelligence traits between spouses, has been received much less attention despite its potential importance as an indicator of mutual mate choice [13,14, 23-29, 36]. It can affect the genetic structure of a population by increasing genetic variance and also homozygosity, although only when few loci are involved. It has been reported that all observed assortative mating in IQ and personal traits might well be due to initial assortment [25]. Some indirect evidence is presented that assortative mating may codetermine patterns of affectedness in dyslexia families with regarding to reading and spelling [26]. Another study that measured verbal and nonverbal intelligence showed that couples were similar in almost all the measured traits, even after controlling for age and education level and there was moderate similarity in education and verbal intelligence possibly due to assortative mating [16]. Wainwright et al. (2005) used the univariate analysis to indicate a positive phenotypic assortative mating and the phenotypic and genetic correlations between the Queensland Core Skills Test (QCST) and Verbal IQ were significantly stronger than the phenotypic and genetic correlations between the QCST and performance IQ [29].

This study has several strengths. First, we examined 8 traits in academic achievements and IQ and found 6 of them showed significant spousal correlations. Secondly, we used PC score to test the relationship for academic achievements and IQ between spouses. PCA is a useful statistical technique that has found application in fields such as face recognition and image compression, and is a common technique for finding patterns in data of high dimension [37]. However, instead of using PCA to study the achievements and IQ, other methods like univariate analysis have been used to indicate a positive phenotypic assortative mating [29] or ANCOVA for studying IQ in 
childhood [28]. To our knowledge, our analysis using PCA represents the first attempt to assess spousal concordance in academic achievements and IQ. It has been suggested that spouse similarity was found for temperament, personality and psychiatric symptomatology that were largely independent highlights the necessity of simultaneous assessment of psychiatric domains in the search for the underlying characteristics conditioning nonrandom mate selection [11].

The findings of this study also have several limitations. The sample size is not large and the sample analyzed was not a random population sample collected with the primary goal of analyzing IQ. However, the mean and standard deviation for IQ among the COGA sample and the sibling correlation for the IQ measures, do not deviate considerably from published reports on unselected samples [34].

In conclusion, the study confirms and extends previous studies relating to the spousal concordance in academic achievements and IQ. Regardless of the causes, the presence of spousal concordance on achievements and IQ aspects has important implications for genetic studies in future research. An analysis of assortative mating for academic achievements and IQ may help us to understand the complex genetic and environmental contributions to academic achievements and intelligence.

\section{ACKNOWLEDGEMENTS}

The Collaborative Study on the Genetics of Alcoholism (COGA) (H. Begleiter, SUNY HSCB, Principal Investigator: T. Reich, Washington University, Co-Principal Investigator) includes nine centers where data collection, analysis, and/or storage take place. The nine sites and Principal Investigator and Co-Investigators are: Indiana University (T. -K. Li, J. Nurnberger Jr., P. M. Conneally, H.J. Edenberg); University of Iowa (R. Crowe, S. Kuperman); University of California at San Diego (M. Schuckit); University of Connecticut (V. Hesselbrock); State University of New York, Health Sciences Center at Brooklyn (B. Porjesz, H. Begleiter); Washington University in St. Louis (T. Reich, C. R. Cloninger, J. Rice, A. Goate); Rutgers University (J. Tischfield); and Southwest Foundation (L. Almasy). This national collaborative study is supported by NIH grant U10AA08403 from the National Institute on Alcohol Abuse and Alcoholism (NIAAA). We acknowledge the contributions of the COGA, supported by NIH Grants U10AA08401 and U10AA08403 (NIAAA) and the contributions of all scientists who have provided phenotypic and genotyping data. This study is part of project "Genetic analysis of alcohol dependence and alcohol-related phenotypes in the COGA sample" approved by IRB, East Tennessee State University.

\section{REFERENCES}

[1] Lott, D.F. (1979) A possible for generally adaptive features in the mate selection and sexual stimulation. Psychological Report, 45, 539-546.
[2] Merikangas, K.R. (1982) Assortative mating for psychiatric disorders and psychological traits. Archives of General Psychiatry, 39, 1173-1180.

[3] Low, N., Cui, L. and Merikangas, K.R. (2007) Spousal concordance for substance use and anxiety disorders. Journal of Psychiatric Research, 41, 942-951. doi:10.1016/j.jpsychires.2006.11.003

[4] Wolański, N. (1974) The stature of offspring and the assortative mating of parents. Human Biology, 46, 613-619.

[5] Ginsburg, E., Livshits, G., Yakovenko, K. and Kobyliansky, E. (1998) Major gene control of human body height, weight and BMI in five ethnically different populations. Annals of Human Genetics, 62, 307-322. doi:10.1046/j.1469-1809.1998.6240307.x

[6] Pawlowski, B. (2003) Variable preferences for sexual dimorphism in height as a strategy for increasing the pool of potential partners in humans. Proceedings Biological Sciences, 270, 709-712. doi:10.1098/rspb.2002.2294

[7] Farley, F.H. and Davi, S.A. (1977) Arousal personality and assortative mating in marriage. Journal of Sex and Marital Therapy, 3, 122-127.

[8] Farley, F.H. and Mueller, C.B. (1978) Arousal, personality and assortative mating in marriage: Generalizability and cross-cultural factors. Journal of Sex and Marital Therapy, 4, 50-53.

[9] Heun, R. and Maier, W. (1993) Morbid risks for major disorders and frequencies of personality disorders among spouses of psychiatric inpatients and controls. Comprehensive Psychiatry, 34, 137-143. doi:10.1016/0010-440X(93)90059-D

[10] Feng, D. and Baker, L. (1994) Spouse similarity in attitudes, personality, and psychological well-being. Behavior Genetics, 24, 357-364. doi:10.1007/BF01067537

[11] Dubuis-Stadelmann, E., Fenton, B.T., Ferrero, F. and Preisig, M. (2001) Spouse similarity for temperament, personality and psychiatric symptomatology. Personality and Individual Differences, 30, 1095-1112. doi:10.1016/S0191-8869(00)00092-1

[12] Luo, S.H. and Klohnen, E.C. (2005) Assortative mating and marital quality in newlyweds: A couple-centered approach. Journal of Personality and Social Psychology, 88, 304-326. doi:10.1037/0022-3514.88.2.304

[13] Hur, Y.M. (2003) Assortative mating for personality traits, educational level, religious affiliation, height, weight, and body mass index in parents of a Korean twin sample. Twin Research, 6, 467-470. doi:10.1375/136905203322686446

[14] Watson, D., Klohnen, E.C., Casillas, A., Simms, E.N., Haig, J. and Berry, D.S. (2004) Match makers and deal breakers: Analyses of assortative mating in newlywed couples. Journal of Personality, 72, 1029-1068. doi:10.1111/j.0022-3506.2004.00289.x

[15] Sutton, G.C. (1980) Assortative marriage for smoking-habits. Annals of Human Biology, 7, 449-456. doi:10.1080/03014468000004561

[16] Wilson, S.E. (2002) The health capital of families: An investigation of the interspousal correlation in health status. Social Science and Medicine, 55, 1157-1172. doi:10.1016/S0277-9536(01)00253-2

[17] Bloch, K.V., Klein, C.H., de Souza e Silva, N.A., Nogueira Ada, R. and Salis, L.H. (2003) Socioeconomic aspects of spousal concordance for hypertension, obesity, and 
smoking in a community of Rio de Janeiro, Brazil. Arquivos Brasileiros de Cardiologia, 80, 179-186. doi:10.1590/S0066-782X2003000200006

[18] Merikangas, K.R. and Brunetto, W. (1996) Assortative mating and psychiatric disorders. Balliere's Clinical Psychiatry International Practice and Research, 2, 175-185.

[19] Maes, H.H., Neale, M.C., Kendler, K.S., Hewitt, J.K., Silberg, J.L., Foley, D.L., Meyer, J.M., Rutter, M., Simonoff, E., Pickles, A. and Eaves, L.J. (1998) Assortative mating for major psychiatric diagnoses in two population-based samples. Psychological Medicine, 28, 1389-1401. doi:10.1017/S0033291798007326

[20] Mathews, C.A. and Reus, V.I. (2001) Assortative mating in the affective disorders: A systematic review and metaanalysis. Comprehensive Psychiatry, 42, 257-262. doi:10.1053/comp.2001.24575

[21] Smith, C.A. and Farrington, D.P. (2004) Continuities in antisocial behavior and parenting across three generations. Journal of Child Psychology, 45, 230-247. doi:10.1111/j.1469-7610.2004.00216.x

[22] Grant, J.D., Heath, A.C., Bucholz, K.K., Madden, P.A., Agrawal, A., Statham, D.J. and Martin, N.G. (2007) Spousal concordance for alcohol dependence: Evidence for assortative mating or spousal interaction effects. Alcoholism: Clinical and Experimental Research, 31, 717-728. doi:10.1111/j.1530-0277.2007.00356.x

[23] Mascie-Taylor, C.G. and Boldsen, J.L. (1984) Assortative mating for IQ: A multivariate approach. Journal of Biosocial Science, 16, 109-117. doi:10.1017/S002193200001484X

[24] Mascie-Taylor, C.G. and Vandenberg, S.G. (1988) Assortative mating for IQ and personality due to propinquity and personal preference. Behavior Genetics, 18, 339-345. doi:10.1007/BF01260934

[25] Mascie-Taylor, C.G. (1989) Spouse similarity for IQ and personality and convergence. Behavior Genetics, 19, 223-227. doi:10.1007/BF01065906

[26] Wolff, P.H. and Meingailis, I. (1994) Family patterns of developmental dyslexia clinical findings. American Journal of Medical Genetics, 54, 122-131. doi:10.1002/ajmg.1320540207

[27] Halpin, B. and Chan, T.W. (2003) Educational homogamy in Ireland and Britain: Trends and patterns. British Journal of Sociology, 54, 473-495. doi:10.1080/0007131032000143546

[28] Nolan, M.A., Redoblado, M.A., Lah, S., Sabaz, M., Lawson, J.A., Cunningham, A.M., Bleasel, A.F. and Bye, A.M. (2003) Intelligence in childhood epilepsy syndromes. Epilepsy Research, 53, 139-150. doi:10.1016/S0920-1211(02)00261-9

[29] Wainwright, M.A., Wright, M.J., Geffen, G., Luciano, M. and Martin, N.G. (2005) The genetic basis of academic achievement on the Queensland core skills test and its shared genetic variance with IQ. Behavior Genetics, 35, 133-145. doi:10.1007/s10519-004-1014-9

[30] Reich, T. (1996) A genomic survey of alcohol dependence and related phenotypes: Results from the Collaborative Study on the Genetics of Alcoholism (COGA). Alcoholism: Clinical \& Experimental Research, 20, 133A- 137A. doi:10.1111/j.1530-0277.1996.tb01763.x

[31] Wechsler, D. (1997) WAIS -III Wechsler adult intelligence scale. Psychological Corporation, San Antonio.

[32] Wechsler, D. (1981) Wechsler Adult Intelligence Scale Revised. The Psychological Corporation, New York.

[33] Bouchard, T.J. and McGue, M.J. (1981) Familial studies of intelligence: A review. Science, 1055-1059. doi:10.1126/science.7195071

[34] Dick, D.M., Aliev, F., Bierut, L., Goate, A., Rice, J., Hinrichs, A., Bertelsen, S., Wang, J.C., Dunn, G., Kuperman, S., Schuckit, M., Nurnberger, J. Jr., Porjesz, B., Beglieter, H., Kramer, J. and Hesselbrock, V. (2006) Linkage analyses of IQ in the collaborative study on the genetics of alcoholism (COGA) sample. Behavior Genetics, 36, 77-86. doi:10.1007/s10519-005-9009-8

[35] Dick, D.M., Aliev, F., Kramer, J., Wang, J.C., Hinrichs, A., Bertelsen, S., Kuperman, S., Schuckit, M., Nurnberger, J. Jr., Edenberg, H.J., Porjesz, B., Begleiter, H., Hesselbrock, V., Goate, A. and Bierut, L. (2007) Association of CHRM2 with IQ: Converging evidence for a Gene Influencing Intelligence. Behavior Genetics, 37, 265-272. doi:10.1007/s10519-006-9131-2

[36] Berninger, V.W., Nielsen, K.H. and Abbott, R.D., Wijsman, E. and Raskind, W. (2008) Gender Difference in severity of writing and reading disabilities. Journal of School Psychology, 46, 151-172. doi:10.1016/j.jsp.2007.02.007

[37] Smith, L.I. (2002) A tutorial on principal components analysis. http://www.cs.otago.ac.nz/cosc453/student_tutorials/ principal_components.pdf 